\title{
Humidification Performance of Passive and Active Humidification Devices Within a Spontaneously Breathing Tracheostomized Cohort
}

\author{
Nobuto Nakanishi, Jun Oto, Taiga Itagaki, Emiko Nakataki, \\ Mutsuo Onodera, and Masaji Nishimura
}

\begin{abstract}
BACKGROUND: Most heat-and-moisture exchangers (HMEs) for patients with tracheostomy and spontaneously breathing are small and have suction ports that allow some expiratory gas to escape, which loses water vapor held in the expired gas. Recently, a heated-and-humidified high-flow system for spontaneously breathing patients with tracheostomy was developed. Little is known, however, about the humidifying performance of HMEs or heated-and-humidified high-flow systems for spontaneous breathing patients with a tracheostomy. OBJECTIVE: To investigate the humidifying performance of the HMEs and heated-and-humidified high-flow systems for spontaneously breathing patients with tracheostomy. METHODS: Adult spontaneously breathing subjects with tracheostomy and were enrolled when their respiratory parameters and $S_{p o}$, were stable. We measured absolute humidity, relative humidity, and temperature by using a capacitance-type moisture sensor at the outlet of the tracheostomy tube. Heated-and-humidified high flow was delivered via the a humidifier and tracheostomy interface, and a selected HME. The subjects received heated-and-humidified high flow, after which an HME was used for humidification before switching back to a heated-and-humidified high-flow system. RESULTS: Ten subjects ( 5 men, 5 women; mean \pm SD age, $72 \pm 12$ y) were enrolled. The admission diagnoses were neurologic ( 5 subjects), respiratory failure (3), and cardiac arrest (2). The APACHE (Acute Physiology and Chronic Health Evaluation) II score was 24 (interquartile range, 20-27). Tracheostomy was performed on day 7 (interquartile range, 5-11 d) after endotracheal intubation, and the duration of mechanical ventilation was $10 \mathrm{~d}$ (interquartile range, 6-11 d). The temperature with the $\mathrm{HME}$ was $29.9 \pm 1.0^{\circ} \mathrm{C}$ and, during heated-and-humidified high-flow use was $35.3 \pm 0.8^{\circ} \mathrm{C}(P<.001)$. With both the HME and the heated-and-humidified high-flow system, the relative humidity reached $100 \%$; the absolute humidity with HME was $30.2 \pm 1.8 \mathrm{mg} / \mathrm{L}$, and, with the heated-and-humidified high-flow system, was $40.3 \pm 1.8 \mathrm{mg} / \mathrm{L}(P<.001)$. CONCLUSIONS: In spontaneously breathing subjects with tracheostomy, an heated-and-humidified high-flow system achieved higher absolute humidity than did an HME. Key words: heat and moisture exchanger; heated and humidified high flow; tracheostomized patients. [Respir Care 2019;64(2):130-135. ( ) 2019 Daedalus Enterprises]
\end{abstract}

\section{Introduction}

Tracheostomy has a number of advantages, including improved patient comfort, easier oral hygiene, and earlier

Drs Nakanishi, Itagaki, Nakataki, Onodera, and Nishimura are affiliated with Emergency and Critical Care Medicine, Tokushima University Hospital, Tokushima, Japan. Dr Oto is affiliated with Emergency and Disaster Medicine, Tokushima University Hospital, Tokushima, Japan.

The authors have disclosed no conflicts of interest. discontinuation from mechanical ventilation. ${ }^{1}$ Normally, inspiratory gas is heated in the pharynx and trachea: humidity in the trachea has been measured in the range of 36 to $40 \mathrm{mg} / \mathrm{L}$, and the optimal absolute humidity below the carina is $44 \mathrm{mg} / \mathrm{L}\left(100 \%\right.$ relative humidity at $\left.37^{\circ} \mathrm{C}\right) .^{2}$

Correspondence: Masaji Nishimura, Critical Care and Emergency Medicine, Tokushima University Graduate School, 3-18-15 Kuramoto, Tokushima, Japan 770-8503. E-mail: nmasaji@tokushima-u.ac.jp.

DOI: $10.4187 /$ respcare.06294 
Because the upper airway is bypassed in patients who have a tracheostomy, warming and humidification of inspired gases are often inadequate. To prevent destruction of airway epithelium, inadequate airway secretion, and airway

See the Related Editorial on Page 233

obstruction, humidification is necessary. ${ }^{2}$ For mechanically ventilated patients, the American Association for Respiratory Care recommends that absolute humidity of passive humidification be $>30 \mathrm{mg} / \mathrm{L}$ and the absolute humidity of active humidification be between 33 and $44 \mathrm{mg} / \mathrm{L} .{ }^{3}$ The optimal humidity spontaneously breathing for patients with tracheostomy remains unclear.

Humidifying devices are used to compensate for the bypassed functions of the upper airway. Heated humidifiers and heat-and-moisture exchangers (HMEs) are commonly used for patients on mechanical ventilation. When reporting the results of a recent bench study, Chikata et al ${ }^{4}$ found that a heated-and-humidified high-flow system achieved better humidification than did an HME. Little is known, however, about performance of heated-andhumidified high-flow and HME in spontaneous breathing of patients with tracheostomy. We, therefore, carried out a crossover study to investigate the humidification performance of an HME and a heated-and-humidified highflow system in spontaneously breathing tracheostomized subjects.

\section{Methods}

\section{Study Design and Settings}

We conducted a crossover study at Tokushima University Hospital. This study was approved by the clinical research ethics committee (approval 2033). At enrollment, written informed consent was obtained from the subjects or their legal representative.

\section{Study Population}

Adult spontaneously breathing subjects with tracheostomy without ventilatory support were consecutively enrolled. We excluded patients with the following: age $<$ 18 y old; copious secretions that caused expulsion difficulties; severe respiratory or hemodynamic instability; had a requirement for $>1 \mathrm{~L} / \mathrm{min}$ of oxygen or $\mathrm{F}_{\mathrm{IO}_{2}}>$ 0.25 .

\section{Study Protocol}

This study was undertaken to compare the performance of an HME (Trach-Vent+, Gibeck, Sweden; in the man-

\section{QUICK LOOK}

\section{Current knowledge}

Humidification for spontaneously breathing patients with tracheostomy is often poor. Heat-and-moisture exchangers (HMEs) are small and light but do not necessarily supply sufficient water vapor, especially when used with oxygen. Recently, a heated-and-humidified high-flow system for spontaneously breathing patients with tracheostomy was developed.

\section{What this paper contributes to our knowledge}

Inspiratory gas humidity was measured with an HME and a heated-and-humidified high-flow system in spontaneously breathing subjects with a tracheostomy. The heated-and-humidified high-flow system delivered higher humidity than the HME. In the present study, both the HME and heated-and-humidified high-flow system supplied absolute humidity at least higher than the American Association for Respiratory Care recommendations.

ufacturer's specifications: absolute humidity, $27.0 \mathrm{mg} / \mathrm{L}$; dead space, $10 \mathrm{~mL}$ ) and a heated-and-humidified highflow device (MR850 and Optiflow tracheostomy interface, Fisher and Paykel Healthcare, Auckland, New Zealand) in spontaneously breathing subjects with tracheostomy. The HME was used with room air only or with added low-flow oxygen $(1 \mathrm{~L} / \mathrm{min})$. A heated-and-humidified high-flow system delivers $40 \mathrm{~L} / \mathrm{min}$ flow at $\mathrm{F}_{\mathrm{IO}_{2}}$ of 0.21 or 0.25 . The heated humidifier system was set to deliver gas at a water chamber temperature of $37^{\circ} \mathrm{C}$ and end-inspiratory circuit temperature at $40^{\circ} \mathrm{C}$. To lessen the time-series bias, the protocol for each subject comprised 3 phases, each lasted $60 \mathrm{~min}$, in the following order: heated-and-humidified high flow, HME, and heated-and-humidified high flow (Fig. 1).

After each period, we measured the temperature and relative humidity of inspired gas by using a capacitancetype moisture sensor (Moiscope, Senko Medical, Tokyo, Japan) (response time, $3 \mathrm{~s}$ in the range of $40-100 \%$ ) that was calibrated by using a cooler-heater water source (HHC51, Senkoika, Tokyo, Japan). One-way valves prevented mixing of inspired and expired gases (Fig. 2). All signals from the hygrometer led to an analog-digital converter and were recorded at $50 \mathrm{~Hz} /$ channel with data-acquisition software (Windaq, Dataq Instruments, Akron, Ohio). Before taking internal measurements, we recorded the ambient temperature and humidity readings for $20 \mathrm{~s}$. Once stabilized values were obtained for each parameter, inspired gas measurements were recorded for $1 \mathrm{~min}$. Absolute humidity was calculated from the corresponding temperature and relative humidity. ${ }^{5}$ At the end of each phase, we col- 


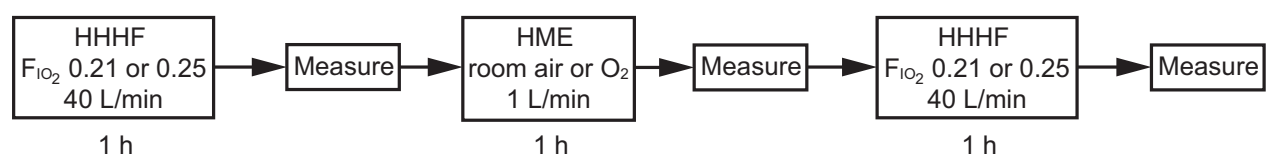

Fig. 1. Time course of measurements. Subjects received heated and humidified high-flow (HHHF), after which a heat-and-moisture exchanger (HME) was used for humidification before switching back to HHHF system.

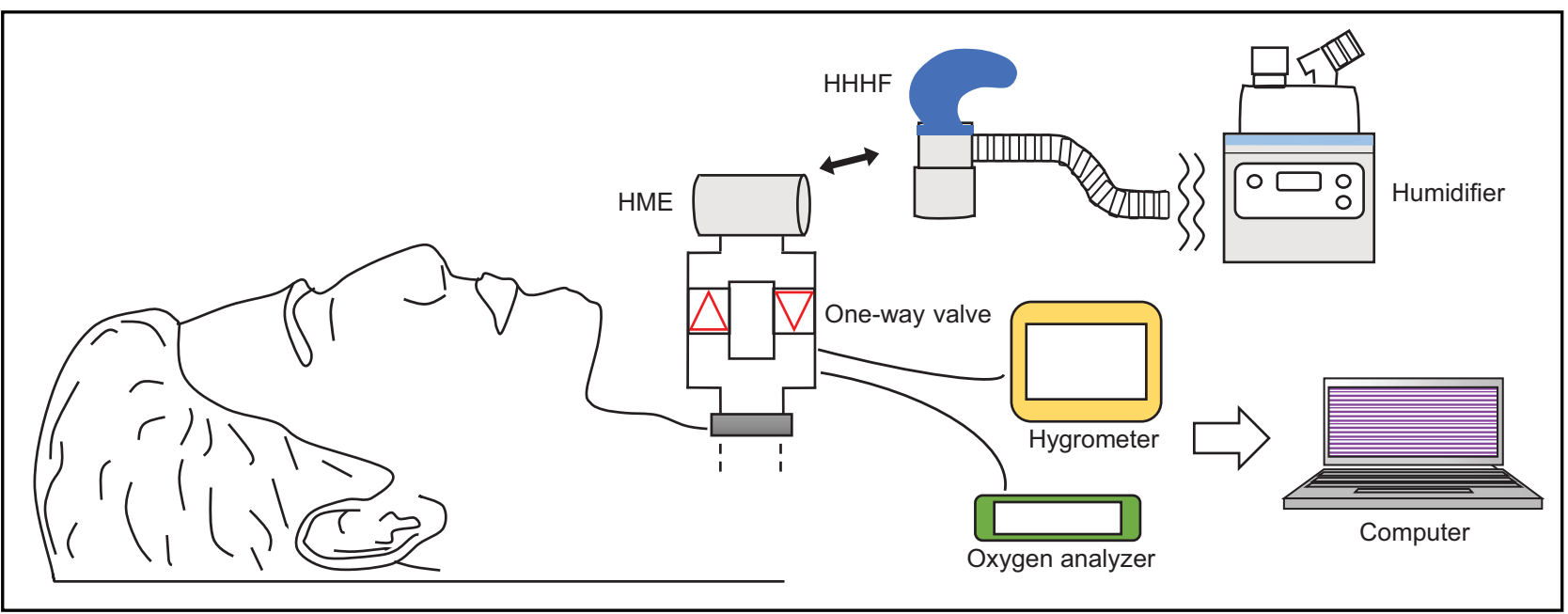

Fig. 2. We measured the temperature and relative humidity of inspired gas by using a capacitance-type moisture sensor. One-way valves prevented mixing of inspired and expired gases. All signals from the hygrometer were sent to an analog-digital converter and recorded at $50 \mathrm{~Hz} /$ channel with data-acquisition software. HME = heat-and-moisture exchanger, HHHF = heated and humidified high-flow.

lected readings for breathing frequency, $\mathrm{S}_{\mathrm{pO}_{2}}$, and hemodynamics (heart rate, systolic blood pressure, and mean blood pressure), and, for $1 \mathrm{~min}$, measured tidal volume $\left(\mathrm{V}_{\mathrm{T}}\right)$ and end-tidal carbon dioxide $\left(\mathrm{P}_{\mathrm{ETCO}_{2}}\right)$ by using an $\mathrm{S} / 5$ Aespire (Dtex-Ohmeda, Helsinki, Finland).

\section{Statistical Analyses}

Normally distributed data are shown as mean \pm SD, whereas non-normally distributed data are presented as median (interquartile range [IQR]). We compared variables obtained during each study phase by using 1-way analysis of variance for repeated measures or the Friedman test. Post hoc correction for multiple comparisons was performed with the Dunnett comparison. Data analysis was conducted by using JMP statistical software version 13.1.0 (SAS Institute, Cary, North Carolina). All statistical tests were 2-tailed, and the chosen type-1 error rate was $P<.05$.

\section{Results}

We enrolled 10 subjects ( 5 men, 5 women; mean \pm SD age, $72 \pm 12 \mathrm{y}$ ). The admission diagnoses were neurologic (5 subjects), respiratory failure (3 subjects), and after cardiac arrest (2 subjects). The APACHE (Acute Physiology and Chronic Health Evaluation) II score was 24 (IQR, 20-27). All the subjects required mechanical ventilation before tracheostomy. Tracheostomy was performed at day 7 (IQR, 5-11 d) after endotracheal intubation, and the total duration of mechanical ventilation was 10 (IQR, 6-11) d. Six subjects did not require oxygen, and 4 required $1 \mathrm{~L} / \mathrm{min}$ of oxygen at $\mathrm{F}_{\mathrm{IO}_{2}}$ of 0.25 . The demographic data are presented in Table 1 .

No statistically significant differences were observed in ambient conditions (Table 2). Temperature with the phase 1 heated-and-humidified high flow system, phase $2 \mathrm{HME}$, and phase 3 heated-and-humidified high-flow system were $35.3 \pm 0.8^{\circ} \mathrm{C}, 29.9 \pm 1.0^{\circ} \mathrm{C}$, and $35.5 \pm 0.8^{\circ} \mathrm{C}$, respectively $(P<.001)$. Relative humidity reached $100 \%$ with both the HME and during heated-and-humidified high flow $(P=.39)$. The mean $\pm \mathrm{SD}$ absolute humidity with the HME was $30.2 \pm 1.8 \mathrm{mg} / \mathrm{L}$ and, with heated-and-humidified high-flow, was $40.3 \pm 1.8 \mathrm{mg} / \mathrm{L}$ (1st phase) and $40.6 \pm 1.7 \mathrm{mg} / \mathrm{L}$ (2nd phase) $(P<.001)$ (Fig. 3$)$.

In phase 1 heated-and-humidified high flow, phase 2 $\mathrm{HME}$, and phase 3 heated-and-humidified high flow, $\mathrm{P}_{\mathrm{ETCO}_{2}}$ was $34.4 \pm 3.7 \mathrm{~mm} \mathrm{Hg}, 35.9 \pm 3.9 \mathrm{~mm} \mathrm{Hg}$, and $34.2 \pm 3.7 \mathrm{~mm} \mathrm{Hg}$, mean $\pm \mathrm{SD}$ respectively $(P=.01)$, and, for minute ventilation, was $6.2 \pm 1.4 \mathrm{~L} / \mathrm{min}$, $7.3 \pm 1.4 \mathrm{~L} / \mathrm{min}$, and $6.0 \pm 1.2 \mathrm{~L} / \mathrm{min}$, mean $\pm \mathrm{SD}$ respectively $(P=.02)$. Heart rate, blood pressure, and $\mathrm{S}_{\mathrm{pO}_{2}}$ 
Table 1. Subjects' Characteristics

\begin{tabular}{lc}
\hline \hline \multicolumn{1}{c}{ Variable } & Result \\
\hline Age, mean \pm SD y & $72 \pm 12$ \\
Men/women & $5 / 5$ \\
Body mass index, median (IQR) $\mathrm{kg} / \mathrm{m}^{2}$ & $21.5(20.0-24.2)$ \\
APACHE II score, median (IQR) & $24(20-27)$ \\
Day of tracheostomy, median (IQR) d & $7(5-11)$ \\
Duration of mechanical ventilation, median (IQR) d & $10(6-11)$ \\
ICU length of stay, median (IQR) d & $11(10-23)$ \\
ICU admission category, $n$ & \\
$\quad$ Neurologic & 5 \\
$\quad$ Respiratory failure & 3 \\
$\quad$ Cardiac arrest & 2 \\
Body temperature, mean $\pm \mathrm{SD}{ }^{\circ} \mathrm{C}$ & $37.4 \pm 0.7$ \\
$\mathrm{~F}_{\mathrm{IO}_{2}} 0.21 / \mathrm{F}_{\mathrm{IO}_{2}} 0.25$ & $6 / 4$ \\
\hline$N=10$. & \\
$\mathrm{IQR}^{\mathrm{A}}$ interquartile range & \\
$\mathrm{APACHE}=$ Acute Physiology and Chronic Health Evaluation II & \\
\hline
\end{tabular}

remained stable across the phases, and the percentage difference of $\mathrm{V}_{\mathrm{T}}$ and breathing frequency were close to $5 \%$.

\section{Discussion}

In this study, we compared the humidification performance of an HME and a heated-and-humidified high-flow device in spontaneously breathing subjects with tracheostomy, and found that the absolute humidity was higher during heated-and-humidified high flow. Because the heated-and-humidified high flow system delivered $>33 \mathrm{mg} / \mathrm{L}$ and the HME delivered $>30 \mathrm{mg} / \mathrm{L}$, both systems satisfied the American Association for Respiratory Care minimum humidification requirements for patients on mechanical ventilation. ${ }^{3}$

However, the International Organization for Standardization $8185^{6}$ recommends an absolute humidity of $>33 \mathrm{mg} / \mathrm{L}$, which is also what Williams et $\mathrm{al}^{2}$ considered the minimum acceptable level of humidity for inspired gases. When comparing 11 HMEs in a bench study, Chikata et $\mathrm{al}^{4}$ found the highest absolute humidity was $30.7 \mathrm{mg} / \mathrm{L}$ with Trach-vent + . After measuring the absolute humidity of 48 HMEs used in mechanical ventilation, Lellouche et $\mathrm{al}^{7}$ reported the average absolute humidity as $27.5 \pm 4.4 \mathrm{mg} / \mathrm{L}$, and the highest as $31.9 \pm 0.6 \mathrm{mg} / \mathrm{L}$. Our current findings with the subjects with tracheostomy showed an HME that delivered comparable levels of absolute humidity as in these bench studies.,7

In the present study, absolute humidity with the heatedand-humidified high-flow system was higher than in our previous bench study. ${ }^{4}$ Four factors may account for the discrepant results. In the bench study, the Airvo 2 delivered $37.7 \mathrm{mg} / \mathrm{L}$ of absolute humidity, ${ }^{4}$ but the absolute humidity in our subjects was $40.3 \pm 1.8 \mathrm{mg} / \mathrm{L}$, mean \pm SD. This higher inspiratory absolute humidity may have resulted from the adaptability of subjects' breathing patterns. Humidification performance varies according to $\mathrm{V}_{\mathrm{T}}$ and breathing frequency. Low $\mathrm{V}_{\mathrm{T}}$ and, possibly, high breathing frequency increase absolute humidity. ${ }^{4} \mathrm{We}$ found a lower $\mathrm{V}_{\mathrm{T}}$ (248 vs $\left.300-500 \mathrm{~mL}\right)$ and higher breathing frequency ( $24 \pm 6$ vs $10-20$ breaths $/ \mathrm{min}$ ) than in our bench study. ${ }^{4}$ The results may also differ owing to the use of 1-way valves to separate expiratory gas; however, we could not completely exclude the possibility of overestimation owing to admixture of water vapor from expired gases.

As discussed previously, it is difficult to measure humidification correctly. ${ }^{8}$ In addition, the environmental conditions differed. At $<100 \%$ relative humidity, absolute humidity is dependent on inspiratory gas temperature. The Optiflow tracheostomy interface connected to the tracheostomy tube was exposed to the ambient temperature, and incoming heated air was cooled at the airway opening of the tracheal tube. ${ }^{9}$ In the study by Chikata et al, ${ }^{10}$ room temperature was lower than in the ICU $\left(24.0^{\circ} \mathrm{C}\right.$ vs $\left.25.0^{\circ} \mathrm{C}\right)$, which possibly resulted in more heat loss. Finally, heatedand-humidified high-flow devices are different. Although the mechanisms are not disclosed, the MR850 humidifier and Airvo 2 have different temperature-control mechanisms; in practice, the Airvo 2 provides better humidification than did the MR850 humidifier.

Several mechanisms may account for the beneficial effects of heated-and-humidified high-flow therapy, such as lower $\mathrm{P}_{\mathrm{ETCO}_{2}}$ and minute ventilation, reductions that might result from decreased lung dead space and better $\mathrm{CO}_{2}$ washout. Breathing frequency and $\mathrm{V}_{\mathrm{T}}$ slightly decreased without statistical significance $(P=.06$ and .08 , respectively), which possibly indicated a little less work of breathing. There also are anatomic differences in the way the gas is delivered by the heated-and-humidified high-flow system and high-flow nasal cannula, which encroach on nasopharyngeal dead space. Heated-and-humidified highflow system supports ventilation directly at the tracheal airway opening, and such proximity to the lung may enable more-effective lung inflation and escape of gas. However, the current investigation was not designed to investigate these effects, and the mechanisms have yet to be resolved.

The cost of the heated-and-humidified high-flow system and the HME should be taken into account. The cost of HMEs is approximately $\$ 2$, and it needs to be changed every 48 h. ${ }^{11}$ However, the cost of a heated-and-humidified high-flow system is higher than an HME because high-flow systems need a tracheostomy interface, heated wire circuit, distilled water, and high-flow oxygen. ${ }^{11}$ However, for patients who are critically ill, the heated-andhumidified high-flow system is justified because it reduces 
Table 2. Effects of HME and HHHF

\begin{tabular}{|c|c|c|c|c|}
\hline Variable & HHHF (1st phase) & HME & HHHF (2nd phase) & $P$ \\
\hline \multicolumn{5}{|l|}{ Ambient condition } \\
\hline Room temperature, median (IQR) ${ }^{\circ} \mathrm{C}$ & $25.0(24.6-26.0)$ & $24.9(24.7-26.0)$ & $25.0(24.6-26.1)$ & .57 \\
\hline Relative humidity, median (IQR) \% & $32.5(13.8-48.7)$ & $31.6(12.9-48.5)$ & $31.1(12.5-47.8)$ & .50 \\
\hline Absolute humidity, median (IQR) $\mathrm{mg} / \mathrm{L}$ & $7.7(3.2-11.3)$ & $7.6(3.0-11.5)$ & $7.4(2.8-11.4)$ & .86 \\
\hline \multicolumn{5}{|l|}{ Subject data } \\
\hline Temperature, mean $\pm \mathrm{SD}{ }^{\circ} \mathrm{C}$ & $35.3 \pm 0.8$ & $29.9 \pm 1.0$ & $35.5 \pm 0.8$ & $<.001$ \\
\hline Relative humidity, median (IQR) \% & $100(100-100)$ & $100(100-100)$ & $100(100-100)$ & .39 \\
\hline Absolute humidity, mean $\pm \mathrm{SD} \mathrm{mg} / \mathrm{L}$ & $40.3 \pm 1.8$ & $30.2 \pm 1.8$ & $40.6 \pm 1.7$ & $<.001$ \\
\hline $\mathrm{P}_{\mathrm{ETCO}_{2}}$, mean $\pm \mathrm{SD} \mathrm{mm} \mathrm{Hg}$ & $34.4 \pm 3.7$ & $35.9 \pm 3.9$ & $34.2 \pm 3.7$ & .01 \\
\hline $\mathrm{V}_{\mathrm{T}}$, median $(\mathrm{IQR}) \mathrm{mL}$ & $248(227-276)$ & $272(244-333)$ & $237(228-283)$ & .064 \\
\hline Frequency, mean $\pm \mathrm{SD}$ breaths/min & $24 \pm 6$ & $26 \pm 5$ & $25 \pm 7$ & .08 \\
\hline$\dot{\mathrm{V}}_{\mathrm{E}}$, mean $\pm \mathrm{SD} \mathrm{L} / \mathrm{min}$ & $6.2 \pm 1.4$ & $7.3 \pm 1.4$ & $6.0 \pm 1.2$ & .02 \\
\hline $\mathrm{S}_{\mathrm{pO}_{2}}$, mean $\pm \mathrm{SD} \%$ & $96 \pm 2$ & $96 \pm 1$ & $96 \pm 1$ & .43 \\
\hline $\mathrm{HR}$, mean $\pm \mathrm{SD}$ beats/min & $85 \pm 16$ & $87 \pm 13$ & $85 \pm 14$ & .14 \\
\hline $\mathrm{SBP}$, mean $\pm \mathrm{SD} \mathrm{mm} \mathrm{Hg}$ & $133 \pm 21$ & $126 \pm 21$ & $130 \pm 27$ & .58 \\
\hline $\mathrm{MBP}$, mean $\pm \mathrm{SD} \mathrm{mm} \mathrm{Hg}$ & $90 \pm 11$ & $87 \pm 11$ & $88 \pm 15$ & .90 \\
\hline $\begin{array}{l}\text { Post hoc Dunnett test vs HME. } \\
\text { HME }=\text { heat-and-moisture exchanger } \\
\text { HHHF }=\text { heated-and-humidified high flow } \\
\text { PETCO }_{2}=\text { end-tidal carbon dioxide } \\
\mathrm{V}_{\mathrm{T}}=\text { tidal volume } \\
\mathrm{V}_{\mathrm{E}}=\text { minute ventilation } \\
\mathrm{HR}=\text { heart rate } \\
\mathrm{SBP}=\text { systolic blood pressure } \\
\mathrm{MBP}=\text { mean blood pressure }\end{array}$ & & & & \\
\hline
\end{tabular}

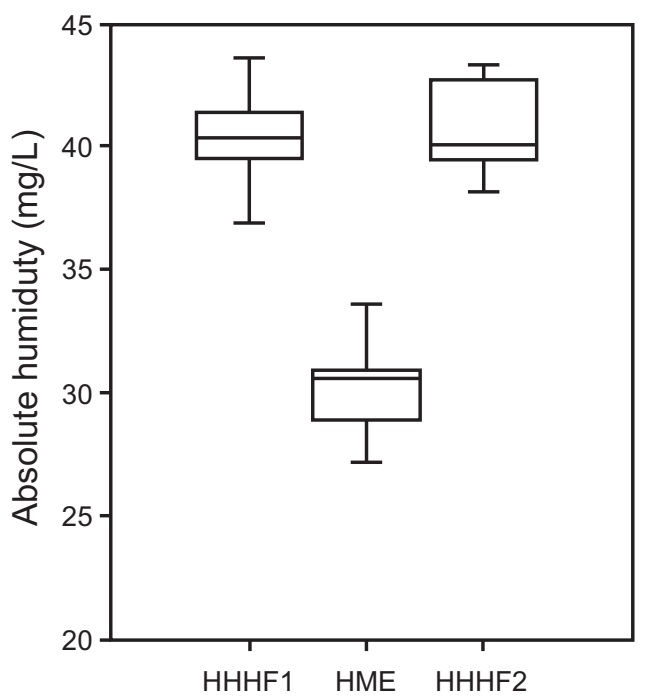

Fig. 3. Absolute humidity during each period. Both devices supplied $>30 \mathrm{mg} / \mathrm{L}$ of vapor, whereas the HHHF system supplied higher vapor. HHHF = heated and humidified high-flow, HHHF1 = HHHF (1st phase), HHHF2 = HHHF (2nd phase), HME = heatand-moisture exchanger.

complications related to inadequate humidity and the risk of re-intubation. ${ }^{12}$

In spontaneously breathing subjects with tracheostomy the absolute humidity was higher during heated-and-hu- midified high flow than with the HME. Humidification is needed in all patients who are critically ill and receiving ventilator support. Even so, the clinical benefits of different methods are still far from being demonstrated and remain to be elucidated. To avoid serious complications related to breathing dry gases, humidifiers should be chosen to provide adequate performance according to clinical conditions.

\section{Limitations}

Our study had several limitations. First of all, the sample size was small. Moreover, all the subjects had a stable respiratory status, and 4 of 10 subjects needed only lowflow oxygen. The absolute humidity would be lower in patients with high $\mathrm{V}_{\mathrm{T}}$ and high inspiratory flow. Our test protocols were also brief. When evaluating the humidifying performance of an HME and a heated-and-humidified high-flow system for spontaneously breathing subjects with tracheostomy, we found higher absolute humidity during heated-and-humidified high flow.

\section{REFERENCES}

1. Cheung NH, Napolitano LM. Tracheostomy: epidemiology, indications, timing, technique, and outcomes. Respir Care 2014;59(6):895915; discussion 916-919. 


\section{Humidification Devices for Tracheostomized Subjects}

2. Williams R, Rankin N, Smith T, Galler D, Seakins P. Relationship between the humidity and temperature of inspired gas and the function of the airway mucosa. Crit Care Med 1996;24(11):1920-1929.

3. American Association for Respiratory Care, Restrepo RD, Walsh BK. Humidification during invasive and noninvasive mechanical ventilation: 2012. Respir Care 2012;57(5):782-788.

4. Chikata Y, Oto J, Onodera M, Nishimura M. Humidification performance of humidifying devices for tracheostomized patients with spontaneous breathing: a bench study. Respir Care 2013;58(9):1442-1448.

5. Tilling SE, Hancox AJ, Hayes B. An accurate method of measuring medical humidifier output. Clin Phys Physiol Meas 1983;4(2):197-209.

6. ISO. Respiratory tract humidifiers for medical use: particular requirements for respiratory humidification systems. 3rd ed. 2007;8185.

7. Lellouche F, Taillé S, Lefrançois F, Deye N, Maggiore SM, Jouvet P, et al; Groupe de travail sur les Respirateurs de l'AP-HP. Humidification performance of 48 passive airway humidifiers: comparison with manufacturer data. Chest 2009;135(2):276-286.
8. Cuquemelle E, Lellouche F. Assessment of humidification performance: still no easy method! Respir Care 2013;58(9):1559-1561.

9. Chikata Y, Imanaka H, Onishi Y, Ueta M, Nishimura M. Humidification during high-frequency oscillation ventilation is affected by ventilator circuit and ventilatory setting. Paediatr Anaesth 2009;19(8): 779-783.

10. Chikata Y, Izawa M, Okuda N, Itagaki T, Nakataki E, Onodera M, et al. Humidification performance of two high-flow nasal cannula devices: a bench study. Respir Care 2014;59(8):1186-1190.

11. Branson RD, Davis K Jr, Brown R, Rashkin M. Comparison of three humidification techniques during mechanical ventilation: patient selection, cost and infections considerations. Respir Care 1996;41(9): 809-816.

12. Eaton Turner E, Jenks M. Cost-effectiveness analysis of the use of high-flow oxygen through nasal cannula in intensive care units in NHS England. Expert Rev Pharmacoecon Outcomes Res 2018;18(3)331-337.

This article is approved for Continuing Respiratory Care Education credit. For information and to obtain your CRCE

(free to AARC members) visit 